\title{
Non-Monotonous Mechanical Behavior at the Nanoscale: Elastic and Plastic Properties
}

\author{
X. Zhanga and E. C. Aifantis ${ }^{\mathrm{a}, \mathrm{b}, \mathrm{c}, 1}$ \\ ${ }^{a}$ School of Mechanics and Engineering, Southwest Jiaotong University, Key Laboratory of Advanced \\ Technologies of Materials, Ministry of Education of China, Chengdu, China \\ ${ }^{\mathrm{b}}$ International Lab for Modern Functional Materials, ITMO University, St. Petersburg, Russia \\ ${ }^{c}$ Lab of Mechanics and Materials, Aristotle University, Thessaloniki, Greece \\ ${ }^{1}$ mom@mom.gen.auth.gr)
}

УДК 539.4

\section{Немонотонное механическое поведение материалов на наноуровне: упругие и пластические свойства}

\author{
Кс. Жанга ${ }^{\mathrm{a}}$ Е. С. Аифантис ${ }^{\mathrm{a}, \tilde{,}, \mathrm{s}}$ \\ а Отделение механики и инжиниринга, Юго-Западный транспортный университет, Лаборатория \\ передовых технологий материалов, Чэнду, Китай \\ ${ }^{\sigma}$ Международная лаборатория современных функциональных материалов, Университет ИТМО, \\ Санкт-Петербург, Россия \\ в Лаборатория механики и материалов, Университет им. Аристотеля, Салоники, Греция
}

Немонотонный характер прочности, объема активации и параметра чувствительности материала к давлению в случае достижения наномасштабных размеров зерна интерпретируется на основании “правила смеси”, которое обычно используется для композитов. Внутренние участки зерна и его граница рассматриваются как две независимыт “фазы” " различными механическими свойствами. Модификачия простого правила смеси путем включения в него конщепций континуальной теории смесей позволяет сгенерировать лапласиан деформации в локальном уравнении состояния для каждой фазы. При постулировании простой одномерной конфигурачии нанополикристалла решается соответствующая краевая задача, что позволяет интерпретировать зависимость общего модуля упругости от размера зерна.

Ключевые слова: наномеханика, нанополикристаллы, градиентные масштабные эффекты.

Introduction. When the mechanical behavior needs to be addressed at the micron and nano scale level, conventional models at the macroscale need to be revised in order to consider the new processes and material states that emerge. It is very well known, for example, that the slope of the conventional Hall-Petch (HP) equation for the yield stress as a linear function of the inverse square root of the grain size, changes from positive to negative. On phenomenological grounds this may be viewed as a "phase transition" that occurs at a characteristic grain size at the range of $\sim 10-20 \mathrm{~nm}$, where about $30 \%$ of the atoms of a nanopolycrystal are situated in the grain boundary space. In that range, a plasticity transition mechanism occurs, as dislocation motion is inhibited in the grain interior and promoted, instead, in the grain boundaries. The classical HP behavior is attributed to the fact that "equilibrium" grain boundaries in conventional polycrystals act as obstacles to the dislocation motion, whereas the inverse HP behavior (IHP) may be 
attributed to the fact that "non-equilibrium" grain boundaries in nanopolycrystals act as facilitators to the dislocation motion within the grain boundary space [1]. A simple "rule of mixtures" relationship for the "bulk" and "grain boundary" space resulted [2-4] to a single non-monotonous equation for the yield stress vs. grain size containing both a hardening and a softening branch.

In Section 1 an analogous procedure is applied to interpret the non-monotonous behavior for the activation volume and the pressure sensitivity parameters of nanophase materials, in agreement with available experimental data.

As shown earlier (e.g., [1]), the "rule of mixtures" argument can be extended to the "continuum theory of mixtures" where both the "grain interior" and the "grain boundary" phases are assumed to behave as their macroscopic counterparts, but they interact with an internal volume force proportional to the relative motion of the two phases. It then turns out that the local stress-strain constitutive equation should be generalized to include the Laplacian of the strain field. This gradient-dependent constitutive equation is used in Section 2 to obtain the variation of the overall "effective" elastic modulus with grain size, for a typical unit cell of a nanopolycrystal and the same can be done for the hardening modulus.

\section{Activation Volume and the Pressure Sensitivity Parameter.}

1.1. Non-Monotonous Behavior of Activation Volume. In conventional polycrystals, grain boundaries act as obstacles to the motion of dislocations, often leading to the formation of piles-up in front of grain boundaries. As a result, the yield or flow stress increased with the decrease of grain size refinement down to around $20 \mathrm{~nm}$, according to the famous HP equation [5]. However, with further reduction of grain size, the pile-up mechanism breaks down and is replaced by other dislocation processes, leading to grain boundary rotation and grain boundary migration [6,7]. As a result, the material softens under further deformation, and below a critical grain size, an IHP behavior is observed. Such type of IHP behavior has been described through a "rule of mixtures" argument [2-4], as well as through a strain gradient plasticity model [8-10].

Recent nanoindenation tests on Ni-W alloy [11] showed that there is a rate dependence of the hardness, i.e., the hardness increases with the increase of the strain rate, following a monotonic linear trend. The strain rate sensitivity is commonly describe through the rate sensitivity index $(m)$

$$
m=\frac{\partial \ln \sigma}{\partial \ln \dot{\varepsilon}}=\frac{\sqrt{3} k_{B} T}{V^{*} \sigma}=\frac{3 \sqrt{3} k_{B} T}{V^{*} H},
$$

where $\sigma$ and $\dot{\varepsilon}$ denote flow stress and strain rate respectively, and the apparent activation volume $V^{*}$ is another physical parameter introduced to characterize the rate-dependent strength or hardness $\left(H=3 \sigma\right.$ according to Taylor's rule), with $k_{B}$ and $T$ denoting Boltzmann constant and temperature, respectively. If then follows that

$$
V^{*}=\sqrt{3} k_{B} T \frac{\partial \ln \dot{\varepsilon}}{\partial \sigma}=3 \sqrt{3} k_{B} T \frac{\partial \ln \dot{\varepsilon}}{\partial H} .
$$

Next, we assume that the strain rate is the same in both grain boundary and grain interior phases, while the total stress is determined by the mixture rule in its classical Voigt form, i.e.,

$$
\sigma=(1-f) \sigma_{g b}+f \sigma_{g} .
$$

In view of Eqs. (2) and (3), the following relationship for the total activation volume $V^{*}$ may be written down, in term of the activation volumes of the grain interior $\left(V_{g}^{*}\right)$ and the grain boundary phase $\left(V_{g b}^{*}\right)$ : 


$$
\frac{1}{V^{*}}=f \frac{1}{V_{g}^{*}}+(1-f) \frac{1}{V_{g b}^{*}}, \quad f=\left(\frac{d-\delta}{d}\right)^{3},
$$

where the expression for the volume fraction $(f)$ of the grain interior phase is easily deduced on the basis of a simple geometric configuration for a nanopolycrystal of grain size $d$ and grain boundary thickness $\delta[2,3]$.

Previous physical arguments for the activation volume in coarse grain metals (based on the intersection mechanism of forest dislocations), give a large for it in the range of $(100-1000) b^{3}$, whereas for grain boundary sliding or grain boundary diffusion (coble creep), the activation volume is estimated as $b^{3}$. For cross slip process, the activation volume may vary between $b^{3}$ and $100 b^{3}$. Grain refinement in nanocrystalline copper $(\mathrm{nc}-\mathrm{Cu})$ results in a rate sensitivity index increase up to an order of magnitude (relative to metals with grain size in the micrometer regime), along with a concomitant decrease in activation volume by two orders of magnitude. The effect of grain size $(d)$ for nc-Cu and twin thickness $(\lambda)$ for $\mathrm{nt}-\mathrm{Cu}$ on the activation volume indicate a decrease from $1000 b^{3}$ to about $10 b^{3}$ when $d$ (or $\lambda$ ) decreases from the micrometer to the nanometer level. Similar tends were observed in other nanocrystalline materials $[11,12]$, where an unusual rate behavior, as manifested through the activation volume parameter, was also reported. These experiments showed that the activation volume first decreased with the refinement of grain size, then increased with decreasing grain size. There was a clear minimum in the activation volume existing near a critical grain size of $10-20 \mathrm{~nm}$. This is reminiscent to the strength transition mentioned earlier from HP to IHP behavior [1-3].

To proceed further we assume as in [1-3] that the grain boundary phase behaves as amorphous material with its activation volume being constant $\left(V_{g b}^{*}=\right.$ const), while the activation volume for the grain interior follows a HP type equation; i.e., $V_{g}^{*-1}=$ $=V_{g}^{\infty-1}+k_{g} d^{-1 / 2}$, as has been observed $[13,14]$ for a wide range of metals with grain size varying from the micron to submicron level. By incorporating the above arguments into Eq. (4) we obtain the following relation for the activation volume of a nanopolycrystal

$$
\frac{1}{V^{*}}=\left(\frac{d-\delta}{d}\right)^{3}\left(\frac{1}{V_{g}^{\infty}}+k_{g} d^{-1 / 2}\right)+\left(1-\left(\frac{d-\delta}{d}\right)^{3}\right) \frac{1}{V_{g b}^{*}} .
$$

This relation provides a good fit to the non-monotonous behavior of the activation volume $V^{*}$ vs. the grain size $d$, as observed experimentally (Fig. 1). To this end, we take $V_{g}^{\infty}=1000 b^{3}, V_{g b}=30 b^{3}$, and $\delta=2 \mathrm{~nm}$, while the value of the parameter $k_{g}$ is to be 0.31 .

1.2. Non-Monotonous Behavior of Pressure Sensitivity. The pressure dependence of yield or flow stress for amorphous and nanophase materials, was been discussed in [15, 16]. It was shown, in particular, that a Mohr-Coulomb criterion can be used to model the anisotropic yielding behavior of nanopolycrystals in tension and compression, as well as the different orientation of shear bands that occur during these different types of loading. This was done by adjusting the value of the friction or pressure sensitivity parameter; i.e., the scalar parameter multiplying the hydrostatic pressure term which is introduced to the usual von Mises stress to modify the yield condition of conventional metal plasticity. More recently, a non-monotonous behavior of the pressure sensitivity parameter of friction coefficient $(\alpha)$ was documented experimentally [11], and also established through molecular dynamics simulation [17]. It will be shown below that the simple "mixture rule" argument 


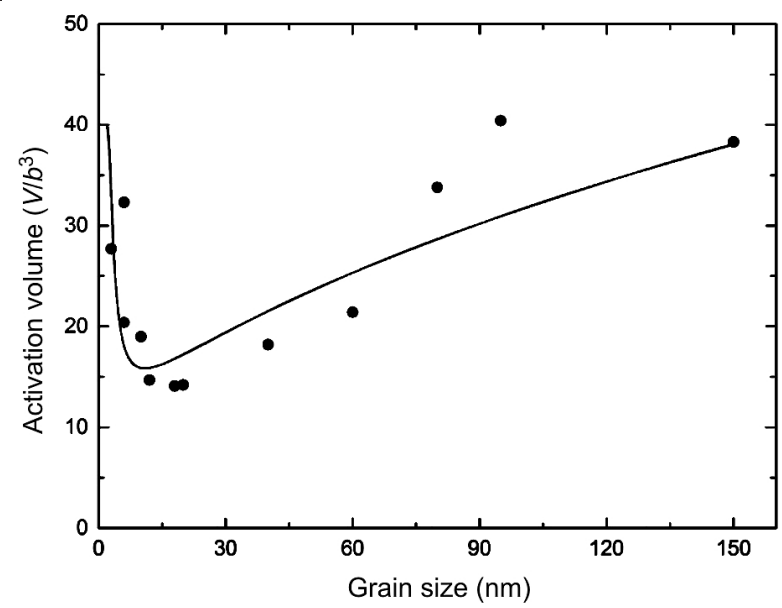

Fig. 1. The grain size-dependent activation volume (normalized by the cubed Burgers vector) of nanocrystalline $\mathrm{Ni}-\mathrm{W}$ alloys [11] fitted through Eq. (5).

used above to model the non-monotonous behavior of the activation volume, can also be utilized to model the aforementioned non-monotonous dependence of $\alpha$ on grain size. The nanopolycrystal is viewed, as before, as a composite containing both "grain boundary" and "grain interior" phases. The overall Mohr-Coulomb friction coefficient $(\alpha)$ can then be expressed as

$$
\alpha=f \alpha_{g}+(1-f) \alpha_{g b}, \quad f=\left(\frac{d-\delta}{d}\right)^{3},
$$

where $\alpha_{g}$ and $\alpha_{g b}$ are the corresponding parameters for the grain interior and grain boundary phases respectively. The volume fraction of the grain interior phase is expressed as before in terms of the grain size $(d)$ and the grain boundary thickness $(\delta)$. The value of $\alpha_{g b}$ is taken as constant $\left(\alpha_{g b}=0.16\right)$, i.e., converges to that for amorphous metals when the grain size is below $10 \mathrm{~nm}$ [11]. The value of $\alpha_{g}$ is assumed to be determined by an HP type relation of the form $\alpha_{g}=\alpha_{g}^{\infty}+k_{g} d^{-1 / 2}$, where $\alpha_{g}^{\infty}$ is the Mohr-Coulomb coefficient for a coarse grain material, which is taken to be equal to 0.02 . Then the overall Mohr-Coulomb friction coefficient $(\alpha)$ for the nanopolycrystal considered herein, reads

$$
\alpha=\left(\frac{d-\delta}{d}\right)^{3}\left(\alpha_{g}^{\infty}+k_{g} d^{-1 / 2}\right)+\left(1-\left(\frac{d-\delta}{d}\right)^{3}\right) \alpha_{g b} .
$$

By assuming the values of $\left(\alpha_{g}^{\infty}, \alpha_{g b}, \delta\right)$ as discussed above and assigning to $k_{g}$ the value of 0.7 we can fit the experimental data of [11], as shown in Fig. 2.

2. Elastic Modulus. Nanoindentation tests [18] have demonstrated that the Young modulus of nanocrystalline $\mathrm{Fe}$ - prepared by mechanical milling/alloying with variable grain size $(7,14.6,20.6$, and $80 \mathrm{~nm})$ obtained through annealing at different temperatures decreases with reduced grain size. This dependence of the Young modulus on grain size is consistent with theoretical predictions [18], suggesting that the change in the Young $(E)$ and shear modulus $(G)$ of nanocrystalline materials, free of porosity, with a grain size larger than about $4 \mathrm{~nm}$, should be very limited $(<10 \%)$. It is likely that the reported large decreases in the Young and shear moduli of nanocrystalline materials prepared by gascondensation/vacuum consolidation result from a relatively large volume fraction of pores. 


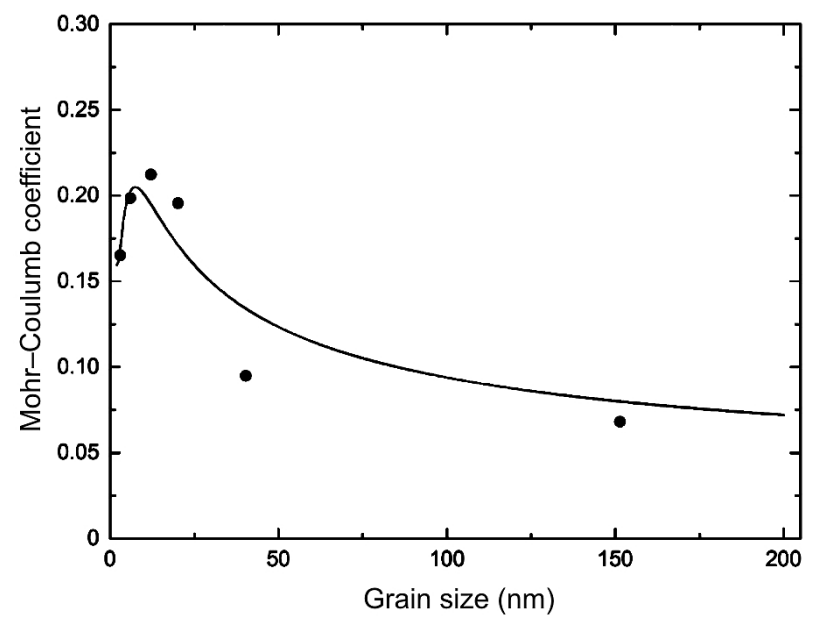

Fig. 2. Comparison of the mixture rule in Eq. (7) to the experimentally measured grain size dependence of Mohr-Coulomb friction coefficient or pressure sensitivity parameter.

Topologically, a nanopolycrystal may be viewed as consisting of three superimposed components: grain interior, grain boundary and triple junctions. Thus, the overall elastic modulus $X$ ( $X$ denotes $E$ or $G$ ) of a nanopolycrystal, may be estimated through the mixture rule [18] as

$$
X=V_{c} \times X_{c}+V_{g b} \times X_{g b}+V_{t j} \times X_{t j},
$$

where $X_{c}, X_{g b}$, and $X_{t j}$ denote elastic modulus for the grain interior, the grain boundary, and the triple junctions, respectively. The corresponding volume fractions denoted here by $V_{c}, V_{g b}$, and $V_{t j}$, can be calculated based on a three-dimensional tetrakaidecahedral representation [19] of the nanopolycrystal as

$$
V_{g b}=\frac{3 \delta(d-\delta)^{2}}{d^{3}}, \quad V_{c}=\left(\frac{d-\delta}{d}\right)^{3}, \quad V_{t j}=1-V_{g b}-V_{c} .
$$

If the grain boundary thickness is assumed to be $0.5 \mathrm{~nm}$, a good fit of Eq. (8) to the experimental data is obtained [18]. The mixture model can further predict a decrease by $20 \%$ in $E$ or $G$ when the grain size reduced down to $1.5 \mathrm{~nm}$ [18].

When a nanopolycrystal is viewed as a mixture of interacting phases [1] made up by grain interior and grain boundaries, the following local gradient constitutive equations results

$$
\tau=k_{i}(\gamma)-c_{i} \nabla \gamma^{2}=\tau^{\infty},
$$

for each one of the phases (see Fig. 1 for a representative 1D configuration). The quantity $\gamma$ is the shear strain, $k_{i}(\gamma)$ with $i=1,2$ denote the homogeneous hardening/softening moduli, $c_{i}$ with $i=1,2$ denote the gradient coefficient, and $\tau^{\infty}$ is the applied shear stress experienced by the representative unit cell shown in Fig. 3. If we assume linear elastic behavior, i.e., the solution of Eq. (10) gives

$\gamma_{g}=\frac{\tau^{\infty}}{G_{g}}+C_{1} \cosh \left[\frac{y}{l_{g}}\right]+C_{2} \sinh \left[\frac{y}{l_{g}}\right], \quad \gamma_{g b}=\frac{\tau^{\infty}}{G_{g b}}+C_{3} \cosh \left[\frac{y}{l_{g b}}\right]+C_{4} \sinh \left[\frac{y}{l_{g b}}\right]$, 


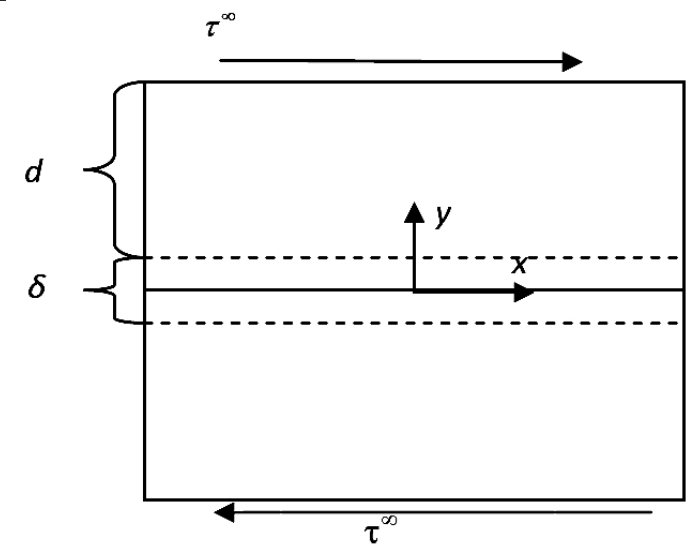

Fig. 3. The illustration of the boundary value problem for the unit cell configuration of a nanopolycrystal under shear.

where $C_{1}, \ldots, C_{4}$ are integration constants and $l_{g}, l_{g b}$ are the internal length scales for the grain interior and grain boundary, i.e.,

$$
l_{g}=\sqrt{\frac{c_{g}}{G_{g}}}, \quad l_{g b}=\sqrt{\frac{c_{g b}}{G_{g b}}} .
$$

The constants $C_{1}, \ldots, C_{4}$ are determined by the following matching (continuity at the interface) and boundary conditions:

$$
\left\{\begin{array}{lll}
\gamma_{\mathrm{g}}=\gamma_{g b} & \text { at } & y=\delta / 2, \\
\frac{d \gamma_{g}}{d y}=\frac{d \gamma_{g b}}{d y} & \text { at } & y=\delta / 2, \\
\frac{d \gamma_{g b}}{d y}=0 & \text { at } & y=0, \\
\gamma_{g}=\frac{\tau^{\infty}}{G_{g}} & \text { at } & y=d+\delta / 2 .
\end{array}\right.
$$

Then, $C_{1}, \ldots, C_{4}$ are given by the following expressions:

$$
\begin{aligned}
& C_{1}=\frac{l_{g}\left(G_{g}-G_{g b}\right) \tau^{\infty} \sinh \left[\frac{\delta}{2 l_{g b}}\right] \sinh \left[\left(\frac{\delta}{2}+d\right) / l_{g}\right]}{l_{g b} G_{g} G_{g b} \cosh \left[\frac{\delta}{2 l_{g b}}\right] \cosh \left[\frac{d}{l_{g}}\right]+l_{g} G_{g} G_{g b} \sinh \left[\frac{\delta}{2 l_{g b}}\right] \sinh \left[\frac{d}{l_{g}}\right]}, \\
& C_{2}=-\frac{l_{g}\left(G_{g}-G_{g b}\right) \tau^{\infty} \cosh \left[\left(\frac{\delta}{2}+d\right) / l_{g}\right] \sinh \left[\frac{\delta}{2 l_{g b}}\right]}{l_{g b} G_{g} G_{g b} \cosh \left[\frac{\delta}{2 l_{g b}}\right] \cosh \left[\frac{d}{l_{g}}\right]+l_{g} G_{g} G_{g b} \sinh \left[\frac{\delta}{2 l_{g b}}\right] \sinh \left[\frac{d}{l_{g}}\right]},
\end{aligned}
$$




$$
\begin{gathered}
C_{3}=-\frac{l_{g b}\left(G_{g}-G_{g b}\right) \tau^{\infty} \cosh \left[\frac{d}{l_{g}}\right] \operatorname{csch}\left[\frac{\delta}{2 l_{g b}}\right]}{l_{g b} G_{g} G_{g b} \cosh \left[\frac{d}{l_{g}}\right] \operatorname{coth}\left[\frac{\delta}{2 l_{g b}}\right]+l_{g} G_{g} G_{g b} \sinh \left[\frac{d}{l_{g}}\right]}, \\
C_{4}=0 .
\end{gathered}
$$

The average strain for the unit cell of Fig. 3 is calculated as

$$
\Gamma=\frac{1}{d+\delta / 2}\left(\int_{0}^{\delta / 2} \gamma_{g b} d y+\int_{\delta / 2}^{d+\delta / 2} \gamma_{g} d y\right)
$$

The first term gives

$$
\int_{0}^{\delta / 2} \gamma_{g b} d y=\tau^{\infty}\left[\frac{\delta}{2 G_{g b}}+\frac{l_{g b}^{2}\left(G_{g b}-G_{g}\right)}{l_{g b} G_{g} G_{g b} \operatorname{coth}\left(\frac{\delta}{2 l_{g b}}\right)+l_{g} G_{g} G_{g b} \tanh \left(\frac{d}{l_{g}}\right)}\right],
$$

whereas the second term gives

$$
\int_{\delta / 2}^{d+\delta / 2} \gamma_{g} d y=\tau^{\infty}\left[\frac{d}{G_{g}}+\frac{2 l_{g}^{2}\left(G_{g}-G_{g b}\right) \sinh ^{2}\left(\frac{d}{2 l_{g}}\right) / \cosh \left(\frac{d}{l_{g}}\right)}{l_{g} G_{g} G_{g b} \tanh \left(\frac{d}{l_{g}}\right)+l_{g b} G_{g} G_{g b} \operatorname{coth}\left(\frac{\delta}{2 l_{g b}}\right)}\right] .
$$

Thus, the overall or "effective" modulus $\left(G_{\text {eff }}\right)$ for the representative macroscopic unit cell can be calculated in a similar form as in [10] giving

$$
G_{e f f}=\frac{\tau^{\infty}}{\Gamma}=\frac{1}{\left[\frac{f_{g b}}{G_{g b}}+\frac{f_{g}}{G_{g}}+\frac{1}{d+\delta / 2}\left(\Theta_{g}+\Theta_{g b}\right)\right]},
$$

where $f_{g}=d /(d+0.5 \delta)$ and $f_{g b}=0.5 \delta /(d+0.5 \delta)$ are the fraction of the grain phase and grain boundary phase, while $\Theta_{g}$ and $\Theta_{g b}$ are the gradient contribution to the effective modulus, given by

$$
\Theta_{g}=\frac{2 l_{g}^{2}\left(G_{g}-G_{g b}\right) \sinh ^{2}\left(\frac{d}{2 l_{g}}\right) / \cosh \left(\frac{d}{l_{g}}\right)}{l_{g} G_{g} G_{g b} \tanh \left(\frac{d}{l_{g}}\right)+l_{g b} G_{g} G_{g b} \operatorname{coth}\left(\frac{\delta}{2 l_{g b}}\right)},
$$




$$
\Theta_{g b}=\frac{l_{g b}^{2}\left(G_{g b}-G_{g}\right)}{l_{g} G_{g} G_{g b} \tanh \left(\frac{d}{l_{g}}\right)+l_{g b} G_{g} G_{g b} \operatorname{coth}\left(\frac{\delta}{2 l_{g b}}\right)} .
$$

It is noted that the gradient contribution to the effective modulus disappears $\left(\Theta_{g}=\Theta_{g b}=0\right)$ when the modulus of the grain boundary phase is the same with the grain interior phase $\left(G_{g}=G_{g b}\right)$.

The above model can be used to capture the grain size dependence of the effective elastic modulus for Fe. To this end, we assume $\delta=1 \mathrm{~nm}, G_{g b}=0.75 G_{g}$ as inferred from atomistic simulations [20]; $l_{g}=2 \mathrm{~nm}$ and $l_{g b}=0.75 \mathrm{~nm}$. The predicted normalized shear modulus $G_{\text {eff }} / G_{g}$ as a function of the grain size, is depicted in Fig. 4a. From this figure, it can be concluded that the elastic modulus may decrease up to $10 \%$, when the grain size is reduced to below $5 \mathrm{~nm}$. Such drop is not as large as that reported earlier [21], where a decrease of about $54 \%$ for nanocrystalline Pd with a grain size of $5 \mathrm{~nm}$ and of about $40 \%$ for nanocrystalline $\mathrm{Cu}$ with a grain size of $25 \mathrm{~nm}$, was reported. Such large reductions of elastic moduli are supposed to result from the processing methods (gas-condensation/ vacuum consolidation) inducing a relatively large volume fraction of pores [18]. The reduction effect of porosity on the elastic modulus was also confirmed through molecular dynamics (MD) simulations [22]. It was shown, for example, that a $12.5 \%$ porosity gives a reduction of $35-40 \%$ in the Young modulus.

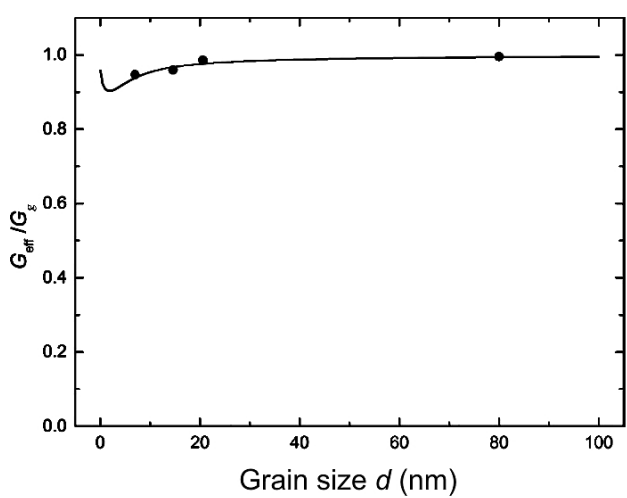

a

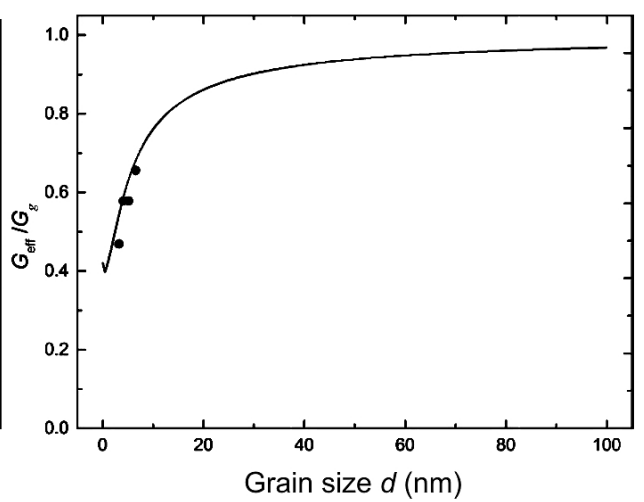

$\mathrm{b}$

Fig. 4. Comparison of the strain gradient model predictions for the grain size dependence of elastic modulus to the experimental data: (a) nanocrystalline $\mathrm{Fe}[18]$ and (b) nanocrystalline $\mathrm{Cu}$ [22].

The elastic moduli resulting from the MD simulations of [22] show that for nanocrystalline $\mathrm{Cu}$ with grain sizes of 3.28, 4.13, 5.21, 6.56 and $13.2 \mathrm{~nm}$, the corresponding Young modulus is obtained as $60,74,75,84$, and $98 \mathrm{GPa}$. It should be noted that these MD simulations underestimate the elastic modulus due to the fact that some plastic deformation occurs (in an initial linear regime of $0.3 \%$ strain which cannot be avoided). These particular $\mathrm{MD}$ results for nc-Cu can also be derived by adopting the above discussed strain gradient model by properly adjusting the internal length parameters. The grain boundary thickness is again assumed to be $\delta=1 \mathrm{~nm}$, while the internal lengths for the grain interior and the grain boundary phases are assumed to be $l_{g}=1 \mathrm{~nm}$ and $l_{g b}=0.25 \mathrm{~nm}$, respectively. By also assuming that the elastic modulus for the grain boundary phase is about $25 \%$ of that for the grain interior phase (i.e., $G_{g b} / G_{g}=0.27$ ) we can obtain a good fit of the strain gradient model to the simulation results, as shown in Fig. 4b. In this connection, it is noted from the 
above simulations, that when the grain size is approaching the internal length scale of the grain interior ( $2 \mathrm{~nm}$ for nanocrystalline $\mathrm{Fe}, 1 \mathrm{~nm}$ for nanocrystalline $\mathrm{Cu}$ ), there is a reverse trend of the elastic modulus, which increases with further decrease of the grain size. In order to illustrate this non-monotonous behavior, we keep the parameters, $G_{g b} / G_{g}=0.5$, $\delta=1 \mathrm{~nm}, l_{g b}=1 \mathrm{~nm}$ as constants, while we vary the internal length scale for the grain interior $l_{g}$ as $1,5,10,20,100$, and $1000 \mathrm{~nm}$. The resulting grain size dependence of the elastic modulus is shown as the solid curves in Fig. 5. It is seen that the effective elastic modulus first decreases with the decrease of grain size, then increases with the continued decrease of grain size. Such non-monotonous behavior emerges when the internal length scale for the grain interior is large, as compared to the grain size itself. Such inversed grain size dependence for the elastic modulus has also been observed in cellular solids where the internal length scale is of the order of the cell size [23]. Furthermore, if the internal length scale for the grain boundary phase is changed to be $l_{g b}=0.5 \mathrm{~nm}$, the obtained results are shown as the dashed curves in Fig. 5, i.e., we find that the effective elastic modulus is reduced as compared to the case where $l_{g b}=1 \mathrm{~nm}$. This is to be expected since the elastic modulus contribution from the strain gradient is reduced when $l_{g b}$ is reduced according to Eq. (18).

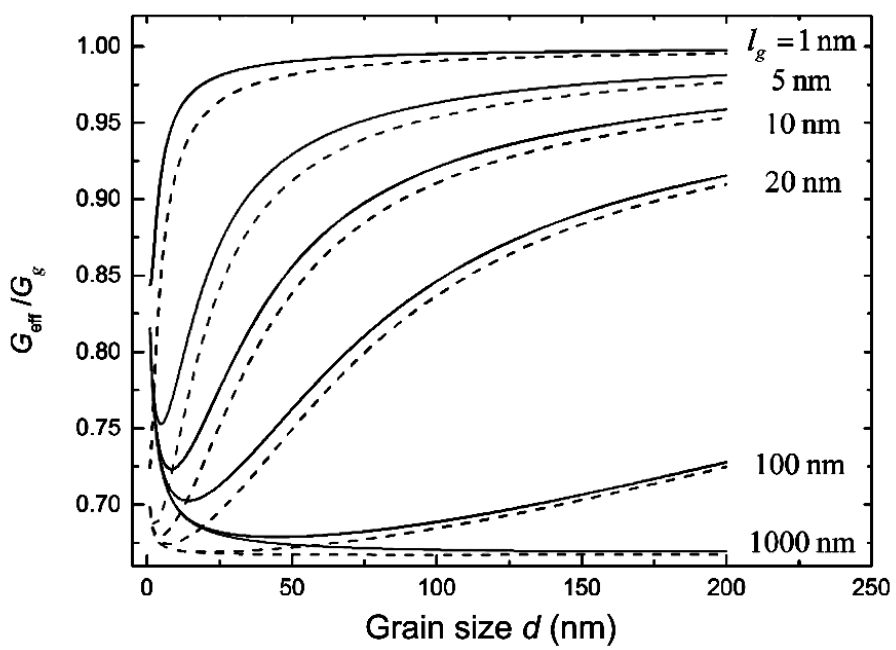

Fig. 5. Grain size dependence of the normalized effective elastic modulus for a nanopolycrystal predicted through the strain gradient model by varying the internal length for the grain interior $\left(l_{g}=1,5,10,20,100\right.$, and $\left.1000 \mathrm{~nm}\right)$ for fixed grain boundary internal length $l_{g b}=1 \mathrm{~nm}$ (solid curves) and $l_{g b}=0.5 \mathrm{~nm}$ (dashed curves).

Conclusions. By viewing a nanopolycrystal as a superposition of two interacting phases (the grain interior and grain boundary phase), it is possible to derive size-dependent expressions for elastic and plastic properties. First, a simple "rule of mixtures" argument is employed to obtain the variation of strength, activation volume and pressure sensitivity parameter on the grain size and the critical size where a transition from the conventional Hall-Petch to and inverse Hall-Petch type behavior is determined. Then, a more elaborate "theory of mixtures" leading to a strain gradient model employed and a typical boundary value problem is solved for a unit cell involving a grain boundary of finite width surrounded by two nanograins. This results to an analytical expression for the overall "effective" elastic modulus which also depends on the grain size, but also as a function of the internal length entering the strain gradient model. The theoretical predictions for all aforementioned nanoscale material properties compare well with available experimental data. 
Acknowledgments. Zhang is grateful for the support of NSFC (11202172), CPSF (2013M530405), the Basic Application Research Plan of Sichuan Province (2015JY0239) and the Sichuan Provincial Youth Science and Technology Innovation Team (2013TD0004). The authors also acknowledge the support of Aristotle University through the Aristeia-II and Hellenic ERC-13 grants of the General Secretariat for Research and Technology (GSRT) of Greece.

\section{Резюме}

Немонотонний характер міцності, об'єму активації і параметра чутливості матеріалу до тиску у випадку досягнення наномасштабних розмірів зерна інтерпретується на основі “правила суміші”, яке зазвичай використовується для композитів. Внутрішні ділянки зерна та його границя розглядаються як дві незалежні “фази” з різними механічними властивостями. Модифікація простого правила суміші шляхом включення у нього концепцій континуальної теорії сумішей дозволяє генерувати лапласіан деформації в локальному рівнянні для кожної фази. При постулюванні простої одновимірної конфігурації нанополікристала розв'язується відповідна крайова задача, що дозволяє інтерпретувати залежність загального модуля пружності від розміру зерна.

1. E. C. Aifantis, "Gradient nanomechanics: applications to deformation, fracture, and diffusion in nanopolycrystals," Metall. Mater. Trans. A, 42, No. 10, 2985-2998 (2011).

2. J. E. Carsley, J. Ning, W. W. Milligan, et al., "A simple, mixtures-based model for the grain size dependence of strength in nanophase metals," Nanostruct. Mater., 5, No. 4, 441-448 (1995).

3. D. A. Konstantinidis and E. C. Aifantis, "On the 'anomalous' hardness of nanocrystalline materials," Nanostruct. Mater., 10, No. 7, 1111-1118 (1998).

4. V. G. Gryaznov, M. Y. Gutkin, A. E. Romanov, and L. I. Trusov, "On the yield stress of nanocrystals," J. Mater. Sci., 28, No. 16, 4359-4365 (1993).

5. M. A. Meyers, A. Mishra, and D. J. Benson, "Mechanical properties of nanocrystalline materials," Prog. Mater. Sci., 51, No. 4, 427-556 (2006).

6. M. Ke, S. A. Hackney, W. W. Milligan, and E. C. Aifantis, "Observation and measurement of grain rotation and plastic strain in nanostructured metal thin films," Nanostruct. Mater., 5, No. 6, 689-697 (1995).

7. I. Ovid'ko and E. C. Aifantis, "Nanocrystals \& nanomechanics: mechanisms \& models. A selective review," Rev. Adv. Mater. Sci., 35, No. 1-2, 1-24 (2013).

8. X. Zhang and K. E. Aifantis, "Interpreting the softening of nanomaterials through gradient plasticity," J. Mater. Res., 26, No. 11, 1399-1405 (2011).

9. K. E. Aifantis and A. A. Konstantinidis, "Hall-Petch revisited at the nanoscale," Mater. Sci. Eng. B, 163, No. 3, 139-144 (2009).

10. X. Zhang and K. E. Aifantis, "Accounting for grain boundary thickness in the sub-micron and nano scales," Rev. Adv. Mater. Sci., 26, No. 1-2, 74-90 (2010).

11. J. R. Trelewicz and C. A. Schuh, "The Hall-Petch breakdown in nanocrystalline metals: a crossover to glass-like deformation," Acta Mater., 55, No. 17, 5948-5958 (2007).

12. J. R. Trelewicz and C. A. Schuh, "The Hall-Petch breakdown at high strain rates: optimizing nanocrystalline grain size for impact applications," Appl. Phys. Lett., 93, No. 17, 171916-171916-3 (2008). 
13. H. Conrad, "Grain size dependence of the plastic deformation kinetics in $\mathrm{Cu}$," Mater. Sci. Eng. A, 341, No. 1-2, 216-228 (2003).

14. J. Chen, L. Lu, and K. Lu, "Hardness and strain rate sensitivity of nanocrystalline Cu," Scripta Mater., 54, No. 11, 1913-1918 (2006).

15. X. H. Zhu, J. E. Carsley, W. W. Milligan, and E. C. Aifantis, "On the failure of pressure-sensitive plastic materials. Part I: Models of yield \& shear band behavior," Scripta Mater., 36, No. 6, 721-726 (1997).

16. J. E. Carsley, W. W. Milligan, X. H. Zhu, and E. C. Aifantis, "On the failure of pressure-sensitive plastic materials. Part II: Comparisons with experiments on ultra fine grained Fe-10\% Cu alloys," Scripta Mater., 36, No. 6, 727-732 (1997).

17. A. C. Lund and C. A. Schuh, "Strength asymmetry in nanocrystalline metals under multiaxial loading," Acta Mater., 53, No. 11, 3193-3205 (2005).

18. T. D. Shen, C. C. Koch, T. Y. Tsui, and G. M. Pharr, "On the elastic moduli of nanocrystalline $\mathrm{Fe}, \mathrm{Cu}, \mathrm{Ni}$, and $\mathrm{Cu}-\mathrm{Ni}$ alloys prepared by mechanical milling/ alloying," J. Mater. Res., 10, 2892-2896 (1995).

19. G. Palumbo, S. J. Thorpe, and K. T. Aust, "On the contribution of triple junctions to the structure and properties of nanocrystalline materials," Scripta Metall. Mater., 24, No. 7, 1347-1350 (1990).

20. M. D. Kluge, D. Wolf, J. F. Lutsko, and S. R. Phillpot, "Formalism for the calculation of local elastic constants at grain boundaries by means of atomistic simulation," J. Appl. Phys., 67, 2370-2379 (1990).

21. G. W. Nieman, J. R. Weertman, and R. W. Siegel, "Mechanical behavior of nanocrystalline $\mathrm{Cu}$ and Pd," J. Mater. Res., 6, No. 5, 1012-1027 (1991).

22. J. Schiøtz, T. Vegge, F. D. Di Tolla, and K. W. Jacobsen, "Atomic-scale simulations of the mechanical deformation of nanocrystalline metals," Phys. Rev. B, 60, 1197111983 (1999).

23. E. C. Aifantis, "On scale invariance in anisotropic plasticity, gradient plasticity and gradient elasticity," Int. J. Eng. Sci., 47, No. 11-12, 1089-1099 (2009). 